\title{
Progress in the development of Reversed Chloroquine molecules as antimalarial therapy
}

\author{
Steven J Burgess ${ }^{2 *}$, Jane Xu-Kelly ${ }^{1,2}$, Katherine Liebmann', Bornface Gunsaru', Westin Morrill ${ }^{2}$, David H Peyton ${ }^{1,2^{*}}$ \\ From Parasite to Prevention: Advances in the understanding of malaria \\ Edinburgh, UK. 20-22 October 2010
}

\section{Background}

Chloroquine (CQ) resistance in P. falciparum is strongly linked to mutations in the gene pfcrt that gives rise to the protein, PfCRT (P. falciparum chloroquine resistance transporter), located in the parasite's digestive vacuole (DV) membrane [1]. In CQ resistant (CQR) strains, accumulation of CQ is reduced in the DV due to increased efflux [2], relative to CQ sensitive (CQS) malaria.

\section{Method}

We have developed a class of molecules, termed Reversed Chloroquine compounds (RCQs), that are hybrids made up of a chloroquine (CQ) like moiety, and a chemosensitizer (Reversal Agent, RA) against CQR in malaria [3]. Subsequent structure-activity relationship (SAR) work showed the RCQ molecular design to be very flexible. Thus, a large variety of RCQ molecules has been constructed that retain the in vitro efficacy against $P$. falciparum malaria [4].

\section{Results}

The RCQ molecules have been shown to have low- to even sub-nanomolar in vitro $\mathrm{IC}_{50}$ values against both CQR and CQS malaria strains. Here we report on an expanded set of RCQ entities. A subset of these drug candidates has been tested in mouse models of malaria, and found to be capable of reducing the parasite burden to below detectable limits; being able to cure by the oral route. Furthermore, RCQ molecules are shown to have enhanced uptake into CQR parasites. Both cytotoxicity and acute toxicity in mice are favorable, as is Ames evaluation of mutagenicity. hERG binding SAR shows that variation in the RCQ structure can be used to minimize potential cardiotoxicity issues.

\section{Conclusion}

The RCQ approach remains a strong contender to exceed the advantages that $\mathrm{CQ}$ brought to malaria chemotherapy for nearly half a century, before being thwarted by resistance.

\section{Author details}

1Department of Chemistry, Portland State University, Portland, Oregon 97207-0751, USA. ²DesignMedix, Inc., 2828 SW Corbett Avenue, Portland, Oregon 97201, USA.

Published: 20 October 2010

\section{References}

1. Fidock DA, Nomura T, Talley AK, Cooper RA, Dzekunov SM, Ferdig MT, Ursos LM, Sidhu AB, Naudé B, Deitsch KW, Su XZ, Wootton JC, Roepe PD, Wellems TE: Mutations in the $P$. falciparum digestive vacuole transmembrane protein PfCRT and evidence for their role in chloroquine resistance. Mol Cell 2000, 6:861-71.

2. Bray PG, Martin RE, Tilley L, Ward SA, Kirk K, Fidock DA: Defining the role of PfCRT in Plasmodium falciparum chloroquine resistance. Mol Microbiol 2005, 56:323-33.

3. Burgess SJ, Selzer A, Kelly JX, Smilkstein MJ, Riscoe MK, Peyton DH: A chloroquine-like molecule designed to reverse resistance in Plasmodium falciparum. J Med Chem 2006, 49:5623-5.

4. Andrews S, Burgess SJ, Skaalrud D, Kelly JX, Peyton DH: Reversal agent and linker variants of reversed chloroquines: activities against Plasmodium falciparum. J Med Chem 2010, 53:916-9.

doi:10.1186/1475-2875-9-S2-O6

Cite this article as: Burgess et al:: Progress in the development of Reversed Chloroquine molecules as antimalarial therapy. Malaria Journal 2010 9(Suppl 2):06 